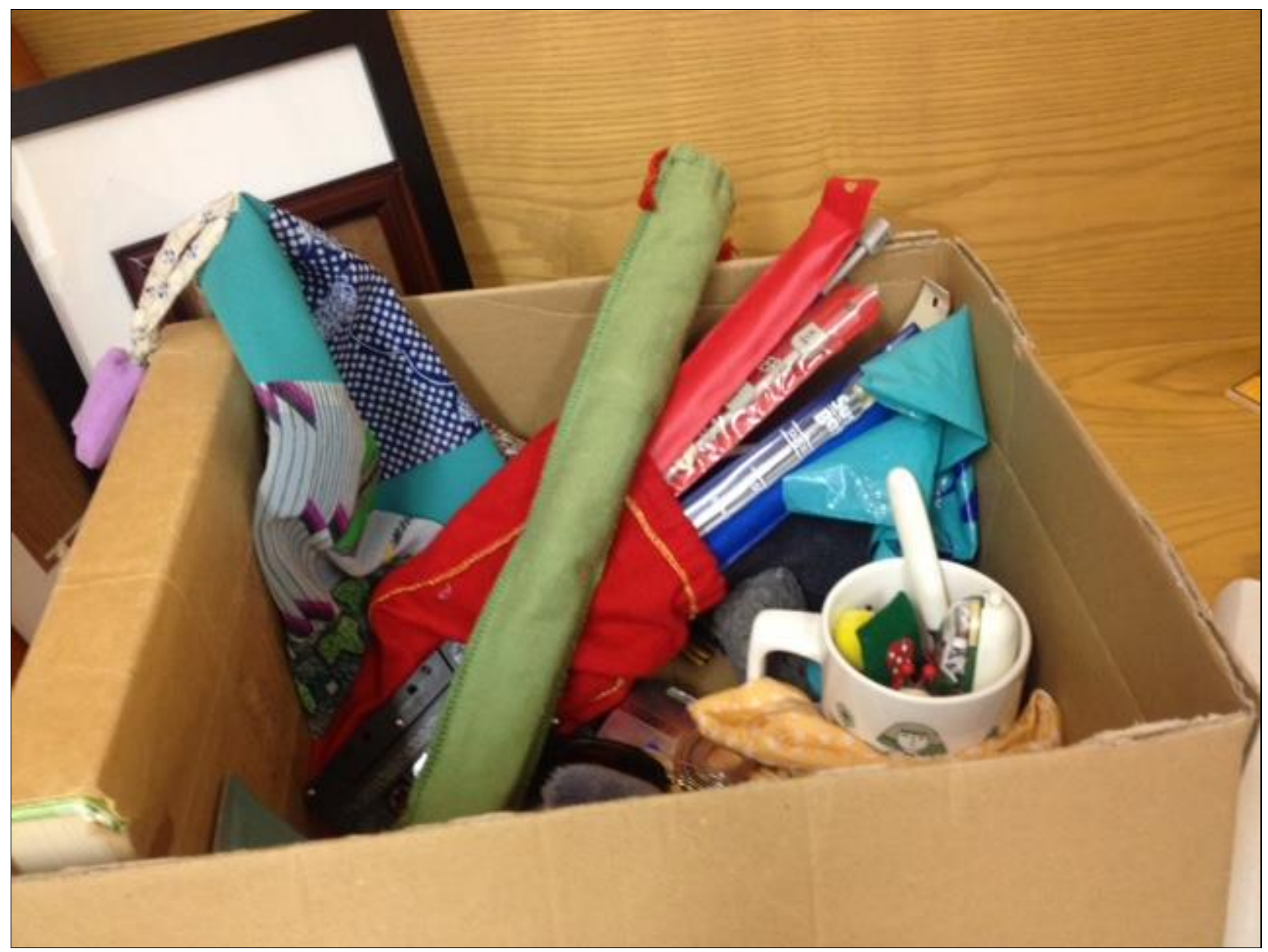

Detail view. Photo credit: Elena Siemens

\title{
Home (Moving) Memory (triptych)
}

Ondine Park

MacEwan University, Canada

A three-part consideration of the ways in which experience, memory, non-memory, the forgettable, the unforgettable, the rememberable, and the unrememberable are made or unmade, activated or suppressed, meaning-imbued or meaning-deprived unevenly in processes of dislocation and reconfiguration. Because notions of self, and particularly a self at home (at ease, in comfort, etc.), are contingently produced within spatial and temporal matrices, the disruption of such conditional layers produce new orientations and disorientations to oneself and the social world in which one finds oneself dis-/em-/re-placed, simultaneously breaking the charm of familiarity and the bounds of the old grounds upon which a former self-making project was staked.

The triptych was comprised of the following pieces: 
Self Contained. Cardboard box containing an assortment of personal items.

This work explores the recurring popular trope of the box-usually long-forgotten or longabandoned-stored in the attic, childhood bedroom closet, or garage, containing various important self-making/self-marking mementos. Such a re-discovered box is imagined as the holder of memories, a reminder of (un)realized/(un)realizable dreams, and the truth of oneself: a past corrective to a present error in self actualization. Despite its assumed access to authenticity, the "box of memories" simultaneously resists interpretation or translatability: To the one who has truly forgotten, or who comes upon someone else's memory box, it is merely an assortment of things that can never add up to a life. For the one who remembers or is reminded, the contents of the memory box holds only the dimmest points in an impossible constellation whose full configuration intersects and stands outside of the containment of the box.

Future Past-Present. 3 unfilled picture frames; 1 unfilled photo album.

The picture frames and photo album gesture towards the "proper" representation-and, literally, framing - of memory but, as with the memory box, suggest the difficulty, ambivalence, performativity, and intersecting impossibilities of memory. The photo frame and album, when filled, present a past; but empty, point to a future in which a past will be made present: memory-work yet to be enacted.

Exorcism. Mouse-trap.

The mousetrap stands in for the exorcism of old spirits, ghosts, memories, beings, and experiences that secretly and mysteriously inhabit and fill the walls of a home. Such a lingering presence is evicted in order to make room for the safe application of new layers of memory-making, self-interpretation, and time- and place-negotiation. The evacuation is inevitably unsuccessful and an unknown remainder forms a haunting substrate upon which the new patterns of dwelling are established. Yet the violence or potential violence of such an extraction must be recognized. As with the mouse, so with other former occupants, dreams, and forces. 